\title{
The Orthography of the Cartoons' Proper Nouns
}

\author{
Dr. Helena Grillo (Mukli) \\ University "Aleksander Moisiu" Durres, Department of Albanian Language, Albania
}

\section{Doi:10.5901/ajis.2015.v4n3s1p472}

\begin{abstract}
The development of the Albanian language has encountered many different issues in three of its subsystems: phonetics, lexicology and grammar. The polemics of the discussions among the linguists on these problems are various and the time has come to analyze not only the noticed changes, but also the factors that have had an impact on them, which sometimes come as social and external factors of the language and sometimes as an internal development of Albanian language. Through a thorough research our study aims to discover the problems that arise from orthography of the proper nouns, mainly found in the children cartoon characters that do not come from the Albanian cartoons.1 Using direct questionnaires with 8-9 years old children, respectively the second and third classes, we collected the data for the use and proper writing of proper nouns of the most favorite cartoons such as Sponger Bob, Patrick, Mickey Mouse, Tom and Jerry, Winnie the Pooh, Sailor Moon, Tweety. We designed a questionnaire with visual photos of the children's cartoons where the children are supposed to write the name of the cartoon in Albanian language. These data serve as the bases for our research on the proper writing of the cartoons' names. The Albanian orthography should tell us the proper way how to write a word and how to use this word the right way in Albanian system. This study brings its contribution in the research of the children language and finds discovers the orthographic problems of the foreign proper nouns.
\end{abstract}

Keywords: children, speech, proper nouns, orthography, pronouncement.

\section{Introduction}

The children's language very often has been on the center of attention regarding the linguistic studies from the psycholinguistic and pragmatic point of view, among the socio-linguistic research too. The objective and persuasive evaluation of the language development is the basis for the early discovery of the kids. Our environment lacks the attitudes and measuring instruments for the language development of the children and the problems that cause the defects learnt during childhood. The study aims to find the relation between the orthography and pronunciation in the children language research mainly in the models of the orthographic norms of the proper nouns that derive from the foreign languages and to discover the consequences of the improper use, in order to help reinstating the right ways of writing. The issues of the study relate to the pronunciation, which in children is learned through the imitation of the adults' language and the impact of the media use of language (mainly listened in the foreign children movies).

The norms of proper pronunciation are part of the development process of the standard Albanian language, they present the state and development of the Albanian language in the specter of the improvement of the Albanian culture in general and the wider areas of the public word, the language of the media etc., which goes closer to the written form by following the writing grammar rules and lexicon during the speech. The language of the social community is always developing being under the influence of the different factors and it never stays in the same level.

\section{A General Overview}

The wide relations with the political and cultural life of other countries pose the issue of the orthographic of the proper nouns ${ }^{2}$. The orthography of the foreign proper nouns is mainly based on their original language pronunciation by adopting the graphic system of the Albanian language. Excluding the $r$, the double consonants of these names are not kept in

\footnotetext{
1 We should emphasize that the Albanian cinematography and cartoons with Albanian characters do not play an important part in the language formation of the Albanian kids, as during the globalization period and the demographic movement this technology has been mainly global. The most known cartoon characters for children are the ones from the animated movies and for children only.

${ }^{2}$ Xh. Lloshi, A problem of orthography, "Drita", 28 June.
} 
Albanian language ${ }^{3}$. According to Xh. Lloshi, when in one text there is a foreign name mentioned for the first time, the name's original form should be included in parentheses. The Albanian orthography does not aim to teach us how to read the foreign languages, especially when this process goes through many manuscripts. For the languages with non Latin origin, there exists an international standard transcription. ${ }^{4}$

The direct contacts with the outside world and the influence of the massive media means are creating a relatively new condition in the relations of the Albanian language with the foreign languages. A very important graphic problem that comes from the new names is the adding of the words in foreign language, mainly american-british which have the letter w. Recently, there are many of these words foreign proper words that have entered into the Albanian use of words.

According to Gj. Shkurtaj adding such foreign names is bringing the necessity of considering the letter $/ \mathrm{w} /$ in Albanian language. The rules of orthography in Albanian language starting from the time when the letter $W$ was only found in a few names of science personalities as Wat, William, Wilson etc., had resoluted that such names in Albanian had to be used with the letter $U$ (for example Uljam, Nju Jork, Uilson) .

Nowadays, it is a fact that the standard Albanian language is gradually entering in all the communication areas, including the spoken language, so the knowledge of the rules and norms of orthographic is a very important task, especially for the schools, public and private radios and television, theaters and other institutions which directly relate to the users of the spoken language. The term orthographic means the pronunciation of the sounds in different phonetic positions or when these sounds are joined with other sounds. But the variety of problems and issues involved within this notion is far wider. The orthography involves other particular phenomenon of the spoken language such as the position of the accent in the word, despite the fact that it presented in the written form of the language. Apart from this, orthography is closely related to other issues that belong only to the spoken word, as the diction and intonation, which makes the notion of orthographic much wider than requires the proper pronunciation of the phonetic system of the language. The academic pronunciation norms are slowly getting better as a presentation of the general development of the standard language.

\section{Methodology}

The methodology used in the realization of this paper has a complex character and as such it implies a number of elements and techniques, which are based on the basic rules of Albanian language spelling, as well as practical experience in the approach to the language development by keeping on mind the general trends of the Albanian language especially orthography trends.

The persistence to observe the facts consists the main side of Behaviorism, which constitutes the methodological basis of our paper.

We designed a model survey, which helped us research the degree of the possession of spelling rules, mainly writing the proper nouns in a foreign language that come from the world of animated films. During this phase, more than ever, there are concrete measures needed in the field of pragmalinguistics. We note that the model is only suitable for children who only spoke Albanian language.

\section{Questionnaire}

-Put the name of the cartoon beside the figure:
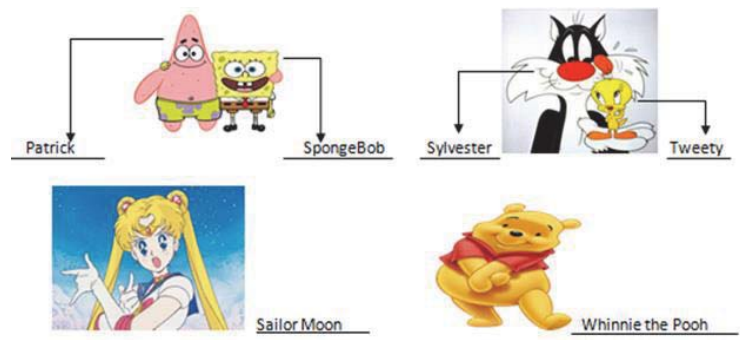

${ }^{3}$ ASHAK, The Albanian proper writing , Prishtine 2005, pg.579 (Prepared from Rexhep Ismajli)

${ }^{4}$ Xh. Lloshi, The Albanian language, a dynamic and open language, Onufri Publishing House, Tirane, 2011, pg.287. 


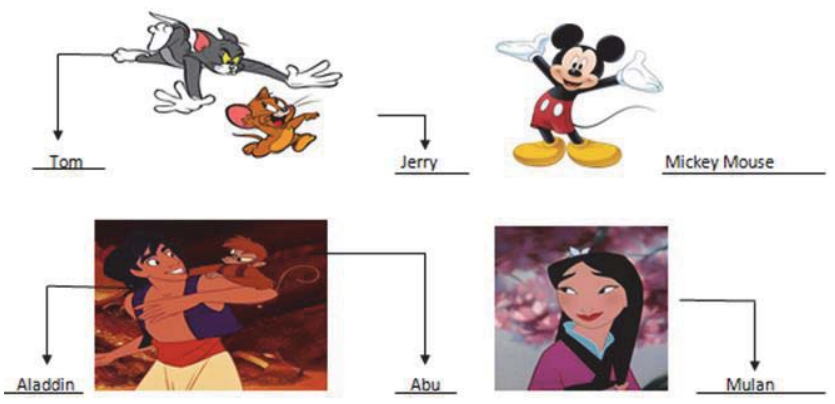

During the selection of the participating children we asked for their data. In the experiment we did not include children who in any way have had difficulties in the psychosocial development aspect. We also excluded the chidren who spoke two languages, those who spend some of their time in a bilingual environment, children who have lived abroad and the ones who have undergone logopedic treatment.

Initially, we tried to see if the children had knowledge about the characters of cartoons.

\section{Hypotheses}

Are the rules of orthography learned in the same level, especially the proper nouns that come from foreign languages?

How does the media and television language affects this learning process?

Up to what extent does the pronunciation affects orthography of the proper nouns?

\section{Results}

The testing is conducted on 60 children divided in the sections and registration of the proper nouns of cartoons. Each of the sections measures the degree of knowledge of the orthography of the proper nouns, where each noun has particular feature related to their spelling, containing the general phonemes: $w, y, o 0, n n$ (double consonants), $r r, a i, o u, g$.

The analyzing of the questionnaires shows that the orthography of the proper nouns in different age groups constitutes one of the issues of Albanian orthography. These age groups tend to be under the influence of television, media and internet and they use more foreign words than Albanian ones. The television transmission of the movies in foreign language affects in the expansion of the forms in foreign language, affecting the orthography of the proper nouns according to the problems stated in the use of phoneme sounds. Keeping in mind the application of the phonetic principle according to which the words and their understandable parts are written in the same way they are spelled, so for each phoneme there is a grapheme. The proper writing is influenced by the direct photography where the child is faced with two different forms: orthographic form and pronunciation form. Very often the children present signs of confusion or doubt between the heard form (the one in the foreign language) and the written form as in the last one the phonetic principle of the Albanian orthographic is not applied. There are general features found which are related with the children's language such as the sounds deformation, adding or dropping of the sounds in the spelling and pronunciation too, but this phenomenon is not part of this study.

From the results of the linguistic analyzes, one of the main factors is the defect of not learning the norm since the childhood, which is proved in the above cases. In a previous study of the author: "The problems of the orthographic norm" it is emphasized that the level of the understanding and use of the orthographic norm is very disturbing. From the $5^{\text {th }}$ up to the $12^{\text {th }}$ grade the learning progression of these norms is inconsiderable, which means that the process of learning Albanian language in schools does not achieve one of its main objectives: the proper learning of the orthographic norms.

Table of Results

\begin{tabular}{|l|c|c|c|}
\hline & The orthographic norm & The pronunciation form & Written in foreign language \\
\hline Sponger Bob & 9 & 14 & 37 \\
\hline Patrick & 12 & 0 & 48 \\
\hline Mickey Mouse & 23 & 35 & 2 \\
\hline
\end{tabular}




\begin{tabular}{|l|c|c|c|}
\hline Tom and Jerry & 5 & 55 & 0 \\
\hline Winnie the Pooh & 4 & 56 & 0 \\
\hline Sailor Moon & 5 & 52 & 3 \\
\hline Tweety & 10 & 50 & 0 \\
\hline
\end{tabular}

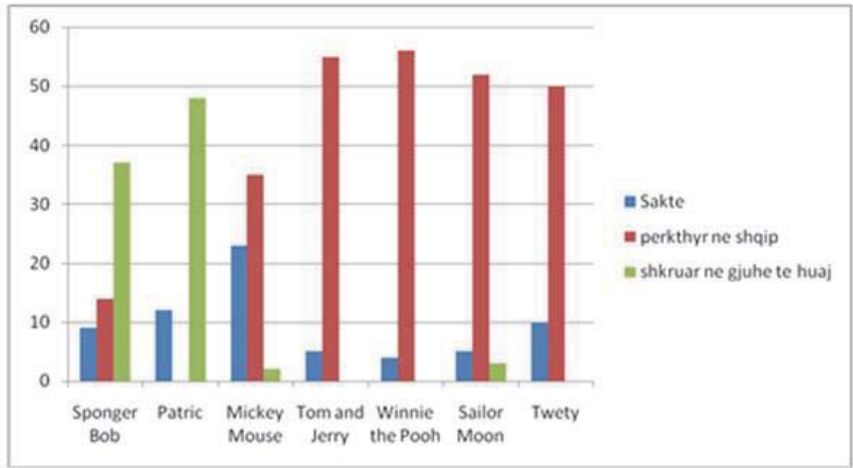

From the analysis of the results we notice that in general the children know very well the pronunciation in Albanian language, which shows that the pronunciation is well acquired.

They use: Sponge Bob, but they show defects in the use of the proper name (Bob instead of Bobby), Tom and Jerry, Winnie the Pooh, Sailor Moon, Tweety. Tom and Jerry is the most popular use of the proper noun. The object of this paper is not to examine the other subsystems of the language, mainly the grammatical system, which will be studied in another paper.

\section{Conclusions}

The use of the language and its communication forms has always presented a complicated process and also very important for the human being. There are many factors that affect and condition the development, the learning and proper understanding of the language and communication.

Many cartoons use the captioned translation which helps the children to differentiate between two languages, as they are firstly aware of the use of two languages and in the same time possess a higher language competency, by separating the variety of the spoken language from the variety of the written one. It is too early for children to understand the application of the morphological principle of the Albanian language, but from the pragmatic point of view, they use easily the proper nouns in different genitives by using the wordforming forms, even though not associated with their proper written forms.

The study provides data for pragmatic research of the language and helps the analyzes of children language and for the designers of the texts of the Albanian language in the direction: orthography and writing. 